\title{
Flood hazard: planning approach to risk mitigation
}

\author{
F. D. Moccia \& A. Sgobbo \\ Department of Urban Planning, Naples University, Italy
}

\begin{abstract}
Control of risks associated with floods in recent years has a central role in urban planning scientific research. This is related to the increased incidence of these phenomena whose the root cause was found in the greater frequency of extreme rainfall events as a result of climate change. In Italy the phenomenon became dramatic because of the numerous human casualties that occur each year. Without prejudice to the need for interventions that effectively act on climate change, there is a need to provide interventions to mitigate the consequences in the short-term. The Department of Urban Planning at Naples University has conducted a thorough research on the case, objectively verifying the impact that human activity has on the dramatic consequences of rainfall events, also highlighting the lack of efficiency of the traditional mitigation measures based on the construction of huge detention basins dug in the ground. This is due to three main reasons: such interventions require financial investments that local communities often do not have; the creation of detention basins cause the removal of large quantities of soil for agricultural use; the continuous increase in impervious surfaces due to urbanization implies the need to cope with the masses of water ever more impressive and therefore the dry ponds already created quickly become insufficient. The research proposes some interventions and best practices that, if adopted, can radically reduce the impact of extreme rainfall on public safety, enabling an efficient participation of private capital in investments through the use of leverage financial and fiscal incentives.

Keywords: flood risk mitigation, anthropogenic activity, impervious surfaces, urbanization, slow-release tanks.
\end{abstract}




\section{Introduction}

Control of risks associated with the occurrence of floods in recent years has taken on a central role in scientific research in the field of urban planning and landscape management. This is related to the increased incidence of these phenomena whose root cause was found in the greater frequency of extreme rain events as a result of climate change.

In Italy the phenomenon has become dramatic because of the numerous human casualties that occur each year with events that also have a strong impact in terms of economic damage to the community. The studies show that over the past ten years, the floods that have resulted in deaths and destruction in our country have been 24 with 428 deaths and more than seven billion Euros of direct damage. At least another eleven billion Euros were lost due to the freeze on production suffered by the affected companies and because indirect damage suffered by the companies armature for the cancellation of orders for semifinished products.

Without prejudice to the need for interventions that effectively act on the causes that are driving climate change, whose effects will be, however, very long-term, there is a need to provide interventions to mitigate the consequences of the phenomenon quickly.

The department of Urban Planning at Federico II University has conducted a thorough research on the case objectively verifying the impact that human activity in transforming the land for their own needs has on the dramatic consequences of rainfall events, also highlighting the lack of efficiency of the traditional mitigation measures based on the construction of huge detention basins dug in the ground.

\section{The impact of human activity on floods frequency}

Human activity on the natural environment affects the occurrence of floods for various reasons. Firstly, because these actions result in climate change, the close relationship existing between human input and climate change is now broadly recognized by the scientific community [1]. The result, from the point of view of rainfall events, is that although the average quantity of water normally falling in the course of a year is substantially constant, if not even slightly reduced, this, on the other hand, is concentrated in a few events particularly intense often associated with rainstorms.

This has serious consequences on the drainage system where there is alternation between long periods of drought and times when there is a need to dispose of abundant water masses.

Urbanization itself has a considerable effect on the rainfall regime resulting in more intense events that occur right where the higher incidence of impervious surfaces leads to the worst consequences. The researchers Steve Burian, University of Arkansas, and J. Marshall Shepherd of NASA's Goddard Space Flight Center, conducted a study [2] to quantify the impact of urbanization on meteorology in the areas surrounding the city of Houston, verifying the actual 
existence of a close correlation between urban density and intensity and frequency of rains.

But the growth and expansion of the urbanized environment is also another anthropogenic cause that adversely affects the floods. In fact, the progressive reduction of the drainage capacity of the soil, due to the construction of roads, buildings and, in general, surfaces of low permeability, determines a considerable increase of the coefficient of influx [3] and, at the same time, the amount of sediment pollutants that disrupt the wholesomeness of water and aquatic environments. The coefficient of influx $\Phi$ is the ratio between the volume of water that reaches the drainage system $\left(\mathrm{W}_{\mathrm{inf}}\right)$ and the total volume of rain $\left(\mathrm{W}_{\text {tot }}\right)[4]$ as in the following eqn (1):

$$
\Phi=\frac{W_{\text {inf }}}{W_{\text {tot }}}
$$

Another effect of the soil low permeability is a strong limitation on the amount of water which regenerates the aquifer reaching the apparent paradox that one of the main causes of floods is also the basis of the phenomenon of the gradual reduction in the quantity of fresh water available for human use.

The main negative effect of urban transformation of the soil on the problem of floods, may, however, be detected in the short time in which the drop of rain reaches the disposal system. This time, normally characterized by calculating the time of concentration, varies in function of topographic and geological characteristics of the basin, but, above all, of the roughness and permeability of surfaces. The concentration time, evaluated at a given point of a network of drainage (natural or artificial), is the time that is necessary to the generic raindrop to reach the closing section of the basin, starting from the farthest point from the hydraulic point of view. It represents a useful measure for predicting the flow of the watercourse that drains a basin resulting from hypothetical rainfall events. The fact that the surface roughness is significant on determining the time of concentration leads to a further important observation: not only the expansion of the city but also its technological evolution influence the impact of urban areas on the risk of floods. The simple analysis of how they have changed, over time, the characteristics of cortical materials typically used in the city, highlights the dramatic evolution of the effect generated by the urban ground, per unit area, on the reduction of the concentration time.

Ultimately, the historic city was not only smaller in size but, with regard to flood risk, had an intrinsic greater resilience [5].

The phenomenon of progressive urbanization goes hand in hand to the abandonment of the agricultural areas remained uncultivated before being incorporated into the city. Even the high percentage of uncultivated areas has a negative impact on flood risk. In a very simple way it can be estimated that, on average about one-third of the water that reaches the Earth's surface in the form of precipitation is returned to scroll directly to the oceans; another third infiltrate into the ground or remaining in the surface layers or resurfacing in waterways, or go down to deeper levels in order to supply potable water resources, and a third, finally, return to the atmosphere by evapotranspiration. 
These percentages, however, are subject to many variables, including geographical location, the rainfall regime, soil type, the saturation degree of the ground, etc. For example, in a typical rural area with land used for agricultural purposes with small slope, the percentage of rainwater that is able to infiltrate into the ground can reach $50 \%, 40 \%$ in evaporation and surface runoff that only the $10 \%$. In an uncultivated area indicated values are $20 \%, 30 \%$ and $50 \%$ on average.

In modern urban areas the ratio of water that infiltrate into the subsoil and water flowing on the surface change dramatically: the runoff grows up to $90 \%$, the infiltration is reduced to values close the zero.

\section{Traditional methods for flood risk mitigation}

The traditional approach to urban drainage involves the collection of all the rainwater falling on the surfaces, more or less impervious, irrespective of their nature and degree of pollution that can cause.

These waters are placed in a disposal system which, in the best of conditions, provides a drain for the ordinary waste water, one for gray water and one for the sewage. Very often the drains for gray water and sewerage are reduced to a single system connected to a sewage treatment plant while rain water is discharged directly into drainage system or sea.

In the regions of southern Italy, focus of the Department of Urban Planning research, the sewer system is actually almost always unique.

In fact each of the above systems presents certain fragility.

Separate sewers have the advantage of reducing considerably the amount of material to be treated in sewage treatment plants. However, the mistaken belief that the waters collected from ordinary urban surfaces can be considered free of pollutants causes quite a few negative effects on the coastal and river aquatic environment.

The double sewer systems have the advantage of ensuring an adequate purification treatment also to the gray water which, although not hypothesized containing dangerous organic residues, actually carry materials that might otherwise not receive an appropriate abatement of polluting power. On the other hand even this system present the same drawbacks listed above with reference to the quality of water discharged directly into natural receptors.

The mixed sewage that, as before stated, in the case investigated in the framework of academic research, are the most frequent, have the advantage of ensuring, at least theoretically, a treatment for all types of water sent to the treatment plant. This, however, only theoretically, as, in fact, on the occasion of heavy rainfall, the water masses that reach the treatment plant are far higher than the actual capacity of the treatment, with the result that part of the sewage is directly poured into the sea as it is.

In any case, none of the systems studied provide any protection against the risk of floods.

This means that the traditional system of flood risk mitigation is based on measures end of pipe and the only prevention activities carried out on the 
drainage system are limited to over-dimensioning of pipelines and the construction of river banks.

The most widely used flood retention system, downstream of the drainage system, is the construction of huge detention basins dug in the ground. But as noted by the relevant scientific literature, these measures often fail to cope effectively with the amount of water resulting from more intense rainstorms demonstrating their usefulness only in those cases which in itself would have caused little damage $[6,7]$.

The system aims to offer a space to temporarily accommodate the masses of excess water in order to allow the rivers and streams to dispose of an amount compatible with their capabilities. The research conducted by the Naples University highlights the lack of efficiency obtainable from this kind of system. This is due to three main reasons: such interventions require huge financial investments that local communities often do not have; the creation of dry ponds cause, as a result, the removal of large quantities of soil for agricultural use; the steady growth of impervious surfaces due to the phenomena of urbanization implies the need to cope with the masses of water ever more impressive and therefore the detention basins already created quickly become insufficient.

\section{Urban planner approach to the mitigation of flood risk caused by city imperviousness}

The complexity of the city implies that a correct approach aimed at reducing the impact that urban areas have on the natural water regime and, in particular, on the management of surface water, can only be a multiplicity of interventions at different scales [8]. You also need to bear in mind that the actors and stakeholders acting in the city system are numerous and animated by different purposes.

Another significant element is that, by now, the phenomena of urbanization and urban sprawl have reached levels far exceeding the tolerance threshold [9] and, therefore, the mitigation measures to be taken absolutely cannot be limited to a virtuous design of expansion areas but they must necessarily also affect the already well established urban fabric.

Therefore the toolset available to the urban planner has recently been enriched by several new best practices.

Those aimed at new development, in general, include infrastructure elements such as street side swales, the use of paving that can ensure good permeability, the waste water disposal systems interwoven with artificial lakes that perform the dual function of landscaping and of regulation elements of water masses to be disposed. At the same time include rules of construction to private developers such as the prohibition of certain types of buildings, the obligation to implement green roofs or to use specific precautions in the management of land devoid of buildings [10].

Measures aimed at the already consolidated urban fabric are in turn grouped into two subgroups: public initiative interventions and private initiative interventions. The first group, although rich in many proposals and extensive 
studies, is characterized by a very low number of direct experience because of the particularly high costs borne by State finances and the difficult relationship between public and private property which is often an insurmountable obstacle, especially in countries where the legal tradition is based on Roman law.

The second group, although not accompanied by equally creative effort on the part of the scientific community may submit, at a time of economic crisis and rigor of the government budget, interesting possibilities of success. It is, mostly, micro interventions at the scale of single ownership or single building, in which the role of the planner becomes central in designing a proper relationship of balance between incentives and effort required. Often, this balance is influenced by ideological conflicts that may cause either excessive burdens for the private (the consequence of which is the lack of action) or a set of rules too gentle (which leads to low efficiency of interventions compared to target).

The research conducted at the Urban Planning Department has identified some interventions potentially applicable and within the second group mentioned above. First, the incentive for the construction of roof gardens; these, in fact, have the advantage of ensuring an efficient filtering action of rainwater that significantly reduces the level of pollutants and dangerous waste by avoiding the need for further downstream processing. At the same time significantly increase the time of concentration by reducing the instantaneous quantity of water transmitted to the urban system of disposal. However it is evident that only a limited part of existing buildings are able to allow this type of interventions without excessive costs.

Another expedient studied concerns the implementation of small tanks at the foot of the individual downspout. In general, the proper technique for the design of rain water drains provides that each vertical pipe serves an area of about 100 square meters.

The available studies on the rainfall regime for southern Italy related to the last twenty years [11] show that more intense rainstorms determine, on average, about $34 \mathrm{~mm}$ of rain water per hour with an average duration of 15 minutes, after which the intensity rainfall is considerably reduced. This means that, to avoid that the water falls on the roofs of buildings reach the urban water disposal system before the phenomenon has reduced the majority of its intensity, it is sufficient to ensure a collection capacity of approximately 0.85 cubic meters.

The product is designed as part of the research program and is constituted by a tank of recycled plastic of dimensions $80 \times 85 \times 150 \mathrm{~cm}$, with a capacity of approximately 0.90 cubic meters. This has two exhaust systems. One, always active, has a flow rate of $2.4 \mathrm{l} / \mathrm{min}$ and allows the complete emptying of the tank in about 6 hours and $15 \mathrm{~min}$. The other, with functions of overflow, has a flow rate of $160 \mathrm{l} / \mathrm{min}$. and allows for disposal of the excess water.

The proposed system, therefore, does not provide for reuse of water collected. In fact, although a traditional expedient of rainwater management involves the reuse such as reloading toilet flushing in the same building, in the consolidated urban fabric this is a serious deterrent in relation to the significant investment in terms of new plumbing to be carried out in the building. 
On the other hand, having recharged groundwater properly, there is no longer the need to save on the water consumption and it is possible to concentrate the efforts to promote the effective implementation of systems to mitigate flood risk by the private sector. In fact the other expedient whose use has been experienced during of the research has just the purpose of providing a considerable supply to groundwater achieving, at the same time the predetermined goal of mitigation. The system consists of absorbing wells dedicated to the disposal of rainwater falling on impervious surfaces often found in large cities. Such a solution was reached by observing that the system traditionally advocated to encourage the return to permeable surfaces presents many difficulties. Very often, in fact, systems such as turf paving grid and permeable pavements are incompatible with the use of large impervious surfaces such as, for example, those of industrial buildings, because of the extreme difficulty of obtaining surfaces capable of supporting the significant loads required.

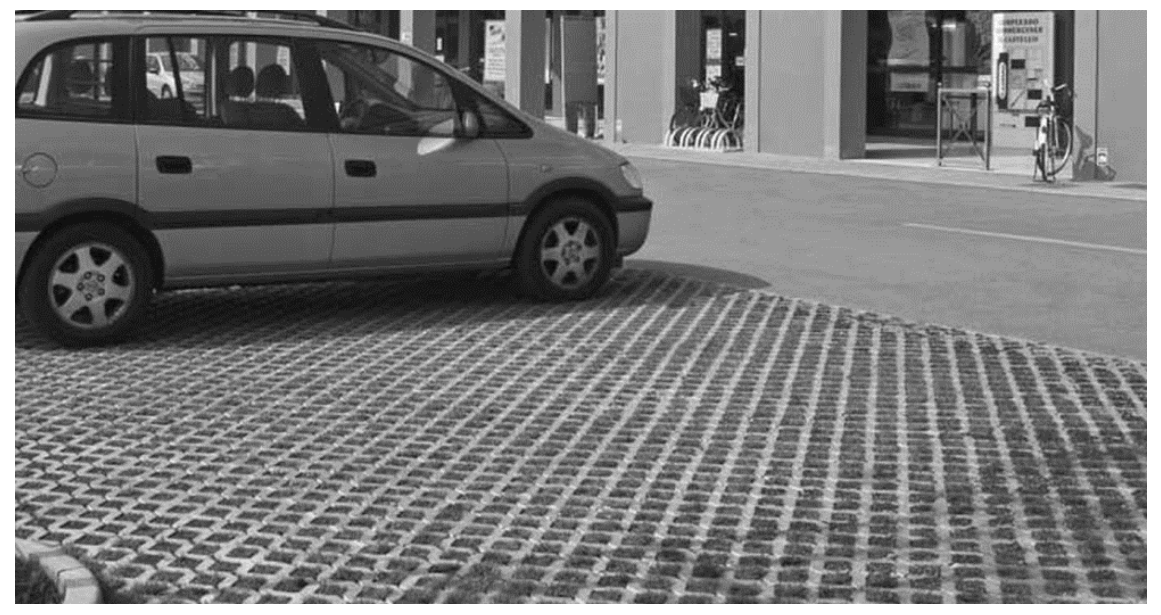

Figure 1: $\quad$ Permeable paver system.

Even for the parking lots of shopping centers, on the other hand, the actual use of paving with high permeability is rather limited because of the significant costs of implementation and the needs of comfortable use by customers. Finally, from the ecological point of view, the use of permeable surfaces for vehicular traffic determines a potential risk of severe pollution of the upper layers of soil.

The solution tested in the research is to achieve absorbing wells, one for every 1,000 square meters of impervious area, aimed to the disposal of rainwater after suitable treatment. This last is the operation that aims to reduce the charge of hydrocarbons and heavy metals and is realized by subjecting to a very simple purification cycle waters that wash away the surface in the first five minutes of rain (after this time it is believed, in fact, that pollutants were now carried away by the first rain and the additional quantities of water can be directly infiltrated into the ground). The process of filtration through the soil will ensure, in any 
case, the further purification of the fluid from any residual contaminants before it reaches the groundwater.

Unlike what was seen with the slow-release tanks provided for buildings, for which it has been possible to design a prototype whose characteristics are suitable for large areas of the region, in the case of infiltrating wells is necessary to design the system in relation to the specific characteristics of the area in which it is realized, however, changing even within the same city. The water of the first five minutes of rain, after purification, is still entrusted to the urban drainage system. The wells, slow-release, are dimensioned with a minimum volume of about 10 cubic meters, are deepened until reaching consisting of layers sufficiently permeable and have a diameter between 20 and $30 \mathrm{~cm}$. They have, such as tanks, one overflow drain able to dispose of excess water during storms of exceptional intensity.

\section{Case study: the basin of the river Sarno}

The territory relating to the former Basin Authority Sarno is delimited to the north, from the foot of Vesuvius, in the South, from the Sorrento Peninsula, to the west by the Gulf of Naples, in the East, from the mountains of Solofra and Pizzo of Alvano.

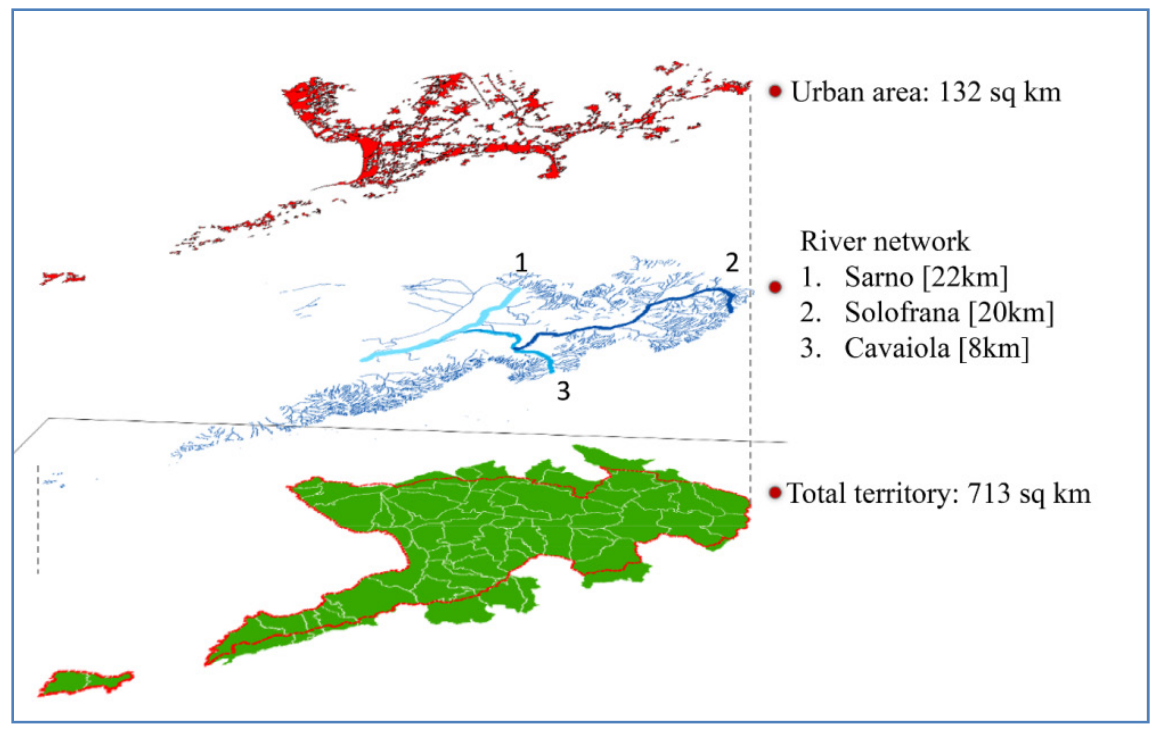

Figure 2: The Sarno basin.

The Basin under investigation extends over an area that occupies a surface of approximately 713 square kilometers The area includes a total of 60 Municipalities. The analysis of population dynamics in the area between 1971 and 2011, as well as the population density, showed a general increase in the 
number of inhabitants, or $15 \%$ for the entire field of study, from a population of $1,102,242$ to the current $1,163,715$. The population density is consistently very high, from 1,174 inhabitants/sq km in 1971 to 1,349 inhabitants/sq km in 2011.

The foothill areas in the territory of relevance Basin Authority Sarno are heavily transformed for the uses and human activities and, often, the construction of settlements, more or less authorized, has also affected areas directly facing the streams and drainage canals of the basin; the result is a situation of risk for flooding that has become intolerable.

The mountain streams are normally completely dry, being only rarely affected by the presence of small natural springs. The presence of water is, therefore, observable only in rainy weathers. As a result of the presence of debris and the occasional run-off of the slopes, the sediment supply to these streams is quite high. In the absence of maintenance, engravings originally present in the bedrock are gradually filling up, resulting in a state of danger related to the possible formation of rivers of mud mixed with debris.

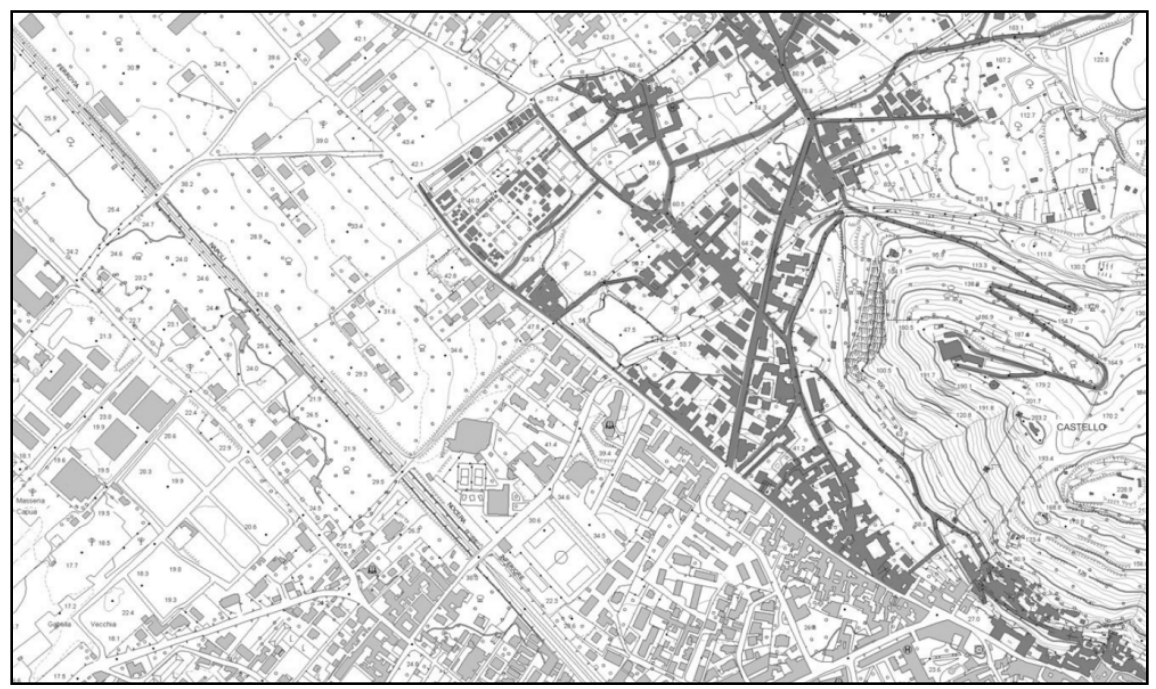

Figure 3: $\quad$ Flood risk in Sarno basin.

For rivers, embedded in the surrounding alluvial plain, risk situations are those that arise primarily from the presence of bottlenecks, such as the numerous bridges often poorly designed, from poor maintenance of the banks and flood walls and because of numerous parts artificially covered in which they may occur occlusions and phenomena of pressure peak.

The critical condition of the drainage basin of Sarno became known to the public following the dramatic events of the flood of 1998. On this occasion, 160 people lost their lives and the economic and environmental damage resulting still have not been fully remediated.

The event, however, put in evidence a state of imminent disaster which, on closer inspection, it is common in many areas of southern Italy. 
The river basin authorities, after a long period of studies and evaluations, has recently approved an action plan that according to the traditional system of flood risk mitigation, is based on the construction of retention basins and areas of expansion. The cost of the project, estimated at about 250 million Euros, is financed almost entirely by the European Regional Development Fund (ERDF 2007-2013).

The main weaknesses of the project approved by the river basin authorities have been identified in the exclusively public investment, which does not involve private investment and felt by people as an imposition, and in the impact that implies in terms of subtraction areas to agricultural activity (about 96 acres).

The experimental project studied during the research conducted by the Department of Urban Planning for the mitigation of flood risk in the basin of Sarno provided that, in lieu of large retention basins, the following actions are proposed: creation of 490 acres of garden roofs; management through the slowrelease tanks of water coming from 4,450 acres of roof; creation of $57 \mathrm{~km}$ of street side swales for disposal of the water coming from roads; 4,080 acres of impervious surfaces managed through systems of absorbing wells.

Particular attention was paid to the economic sustainability of the project. The overall work provides a total cost of 460 million Euros. However, only 95 of these correspond to costs incurred directly by the public budget. The remaining part is borne by the private sector and encouraged through fiscal measures and incentives to operate building transformations.

Fiscal measures are applicable thanks to an already existing law that provide for the maintenance of the housing stock of the consolidated urban fabric, aimed at improving the efficiency and sustainability of buildings, householders bearing the cost can deduct $55 \%$ of it from taxes. Therefore, the part of private investment that can take advantage of deductions is about 271 million Euros, resulting in leverage fund of about 150 million distributed, however, in the next ten years.

The incentives to operate building transformations concern the possibility of expansion and integration of different uses. This also allows you to promote further investments with predictable advantages in terms of overall efficiency and sustainability of the city

\section{References}

[1] Bernhofer, C., Franke, J., Goldberg, V, Seegert, J. and Kuchler, W, Regional Climate Change. To be included in Future Flood Risk Analysis? (Chapter 8). Flood Risk Management: Hazards, Vulnerability and Mitigation Measures, eds. J. Schanze, E. Zeman and J. Marsalek, Springer: Dordrecht, The Netherlands, pp. 93-96, 2006.

[2] Shepherd, J.M. and Burian, S., Detection of Urban-Induced Rainfall Anomalies in a Major Coastal City, Earth Interaction 7, pp. 1-17, 2003.

[3] Rimoldi, P., Ingegneria idraulica urbana. Acquedotti e fognature. Manuale-tecnico pratico per la progettazione e la realizzazione delle opere, Maggioli editore: Santarcangelo di Romagna, Italy, pp. 172, 2010. 
[4] Mishra, S.K. and Singh, V.P., Soil Conservation Service Curve Number (SCS-CN) Methodology, Kluwer Academic Publishers: Dordrecht, The Netherlands, pp. 61-63, 2003.

[5] Perrone, C. and Zetti, I., Il valore della terra. Teoria e applicazioni per il dimensionamento della pianificazione territoriale, Franco Angeli: Milano, Italy, pp. 117-124, 2011.

[6] Schumann, A.H., Flood Risk Assessment and Management: How to Specify Hydrological Loads, Their Consequences and Uncertainties, Springer: London, U.K., pp. 260-263, 2011.

[7] Thorsteinsson, D, Semadeni-Davies, A. and Larsson, R., Planning for River Induced Floods in Urban Areas (Chapter 25). Flood Risk Management in Europe: Innovation in Policy and Practice, ed. S. Begum, M.J.F. Stive and J.W. Hall, Springer: London, U.K., pp. 492-499, 2007.

[8] Martincigh, L., Strumenti di intervento per la riqualificazione urbana. La complessità dell'ambiente stradale, Gangemi Editore: Rome, Italy, pp. 2426, 2012.

[9] Ercolini, M., Cultura dell'acqua e progettazione paesistica, Gangemi Editore: Rome, Italy, pp. 91-92, 2010.

[10] Wagner, I., Marsalek, J. and Breil, P., Aquatic Habitats in Sustainable Urban Water Management: Science, Policy and Practice, Routledge: London and New York, pp. 49-56, 2008.

[11] Polemio, M. and Lonigro, T., Variabilità climatica e ricorrenza delle calamità idrogeologiche in Puglia. Le modificazioni climatiche e $i$ rischi naturali. Atti delle giornate studio, ed. M., Polemio, CNR IRPI: Bari, Italy, pp. 13-15, 2011. 